\title{
Rhizomes in the iField: What Does it Mean to be an iSchool?
}

\author{
Kathleen Burnett* and Laurie J. Bonnici** \\ * Florida State University, College of Communication and Information, \\ Tallahassee, FL 32306-2651 (USA), <kburnett@fsu.edu> \\ ** University of Alabama, College of Communication and Information Sciences, \\ School of Library and Information Studies, Tuscaloosa, AL (USA), <lbonnici@slis.ua.edu>
}
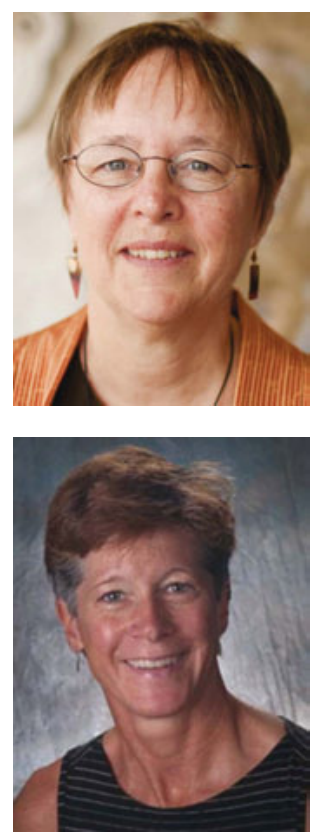

Dr. Kathleen Burnett is a professor and interim director of the Florida State School of Library and Information Studies--Florida's iSchool, where she teaches courses in information science, information behavior, information education, and international and comparative information services. She uses mixed method approaches to investigate sociotechnical issues in information education, information technology use, and professional and disciplinary identity. She is co-editor with Michelle Kazmer of the Journal of Education for Library and Information Science.

Dr. Bonnici is an Associate Professor at The University of Alabama College of Communication and Information Sciences. Her research is focused in two areas: information technologies for universal access as well as disciplinarity and education for information science. Research methods expertise centers on interpretivist approach to investigate user interaction with information and communication technologies for information access. She has served as an investigator on federal and state-funded grants. She is currently lead author on a book with Dr. Kathleen Burnett (FSU) titled "The Study of Information Revisited: Chaos in the Emergence of Disciplinary Identity."

Burnett, Kathleen and Bonnici, Laurie J. Rhizomes in the iField: What Does it Mean to be an iSchool? Knowledge Organization. 40(6), 408-413. 18 references.

Abstract: In 2005, several North American information schools dedicated to advancing the information field (iField) in the $21^{\text {st }}$ century announced the formation of the iSchools organization. The purpose, subsequent growth, and internationalization of this effort might be described as rhizomorphic. This article deploys Deleuze and Guattari's metaphor of the rhizome to describe and analyze recent trends in the development of education for the iField. Characteristics of the iSchools organization are compared to those delineated by Duffy and Cunningham (1996), and conclusions are drawn regarding the applicability of this metaphor to describing the future of the iSchools and the advancement of the iField.

Received and accepted 1 September 2013

\subsection{Introduction}

Abbott (2001) describes the emergence and evolution of a discipline as a gradual process, usually taking three or more decades to crystalize. According to Bruce $(2010,39)$ "for more than forty years, the information field has attempted to articulate clear statements of identity, core values, and distinctive qualities." At the beginning of the $21^{\text {st }}$ century, a small group of 14 North American academic information programs banded together to form an organization (the iSchools) to promote the information field (iField). The goal of the first open meeting of iSchool faculty and stu- dents in 2006 was "to articulate the essence of an information school' and the 'information field." Seven years later, this goal remains elusive. Dillon (2012, 267) writes:

Most descriptions of iSchools reference intellectual focus on the dynamic interaction of people, information and technology (see e.g., Larsen, 2009 [sic. 2010]) with particular emphasis on leveraging the power of technology and information to enhance human and organizational potential. While there are limitations with this operational representation, it is both sufficiently satisfactory for most people who 
recognize the major impact of IT on all our lives, and sufficiently open to allow for variation in application to any one school .... More importantly, by placing emphasis on human activities mediated by information and technology, this articulation shifts the field's focus from agencies of collection such as libraries or archives, which more typically are invoked when describing subject coverage in schools of library and information science, to the contexts in which people, information and technology interact.

As of July 2013, the iSchools roster included 46 members. Today, nearly half of the members (21 iSchools) are located outside North America. Of the 25 in North America, 18 include master's programs accredited by the American Library Association (ALA). The purpose, subsequent growth, and internationalization of the iSchool movement might be described as rhizomorphic. This article deploys Deleuze and Guattari's metaphor of the rhizome to describe and analyze recent trends in the development information education. Characteristics of the iSchools organization are compared to those delineated by Duffy and Cunningham (1996), and conclusions are drawn regarding the applicability of this metaphor to the description of the future of the iSchools and the advancement of the iField.

\subsection{The Rhizome Metaphor}

Deleuze and Guattari first introduced the metaphor of the rhizome in 1976, but it is their use of this concept to frame the readers' experiences of Milles Plateaus (1980, English translation: A Thousand Plateaus, 1987) that is most often referenced. This unusual book forefronts multiplicities and allows for non-hierarchical entry and exit points. "Writing," Deleuze and Guattari (1987, 4-5) claim, "has nothing to do with signifying. It has to do with surveying, mapping, even realms that are yet to come." They distinguish the rhizome from two types of 'arborescent' knowledge representation: the root-book and the radicle-system, which support an essentially monolithic conception of knowledge transfer. In the case of the root-book, knowledge is unitary and stable; while in the case of the radiclesystem, fragmentation and multifariousness emerge. Neither was satisfactory for the postmodern project that Deleuze and Guattari undertook in A Thousand Plateaus. For this purpose they proposed a third system: the rhizome. Deleuze and Guattari (1987, 6-7) write:

A system of this kind could be called a rhizome. A rhizome as a subterranean stem is absolutely different from roots and radicles. Bulbs and tubers are rhizomes. Plants with roots or radicles may be rhizomorphic in other respects altogether... . Burrows are too, in all their functions of shelter, supply, movement, evasion, and breakout. The rhizome itself assumes very diverse forms, from ramified surface extension in all directions to concretion into bulbs and tubers... . The rhizome includes the best and the worst: potato and couchgrass, or the weed.

\subsection{Rhizomes in the iField}

In this article, we extend the application of the rhizome metaphor beyond the boundaries of the technical (Moulthrop 1992; Burnett 1993a and 1993b; Lemke 1993), situating the analysis in the sociotechnical dimensions of the vision of the iSchools - in the relationships between people, information, and technology. As previous analyses using the metaphor have demonstrated, Deleuze and Guattari's rhizome is multi-dimensional: it is multilingual, metapolitical, and sociotechnical. It is therefore an appropriate analytic tool to use to examine the characteristics of an organization that explicitly emphasizes "leveraging the power of technology and information to enhance human and organizational potential" (Dillon 2012, 267).

\subsection{Principles of the Rhizome}

A rhizome ceaselessly establishes connections between semiotic chains, organizations of power, and circumstances relative to the arts, sciences, and social struggles. A semiotic chain is like a tuber agglomerating very diverse acts, not only linguistic, but also perceptive, mimetic, gestural, and cognitive; there is no language in itself, nor are there any linguistic universals, only a throng of dialects, patois, slangs, and specialized languages (Deleuze and Guattari 1987, 7.)

Deleuze and Guattari discuss the rhizome in terms of principles (connection and heterogeneity, multiplicity, asignifying rupture, cartography, and decalcomania), which have been explicated by Burnett (1993a and 1993b), Duffy and Cunningham (1996), and Schuh and Cunningham (2004), among others. Duffy and Cunningham (1996) provide accessible descriptions of the characteristics of the rhizome, which we adopt here to examine whether the character, growth, and trajectories of the iSchools are rhizomorphic, and if so, what this says about the unfolding nature of the iField. These characteristics, according to Duffy and Cunningham $(1996,177)$ include:

1) Every point can and must be connected with every other point, raising the possibility of an infinite juxtaposition.

2) There are no fixed points or positions, only connections (relationships). 
3) The structure is dynamic, constantly changing, such that if a portion of the rhizome is broken off at any point it could be reconnected at another point, leaving the original potential for juxtaposition in place.

4) There is no hierarchy or genealogy contained as where some points are inevitably superordinate or prior to others.

5) The rhizome whole has no outside or inside but is rather an open network that can be connected with something else in all of its dimensions.

Since in many ways the discussion of the first of these characteristics- "every point can and must be connected with every other point, raising the possibility of an infinite juxtaposition"-is dependent upon (or subsumes) the remaining characteristics, we will discuss it last.

\subsection{Are there fixed points or positions?}

While the iSchools together "share a fundamental interest in the relationships between information, people, and technology," individually "each has its own strengths and specializations" (http://ischools.org). The nature and direction of the relationships are diverse, often reflecting the origins of the individual school.

In an article published in the official journal of the Association for Library and Information Science Education (ALISE), Journal of Education for Library and Information Science, Dillon (2012) suggests that three points distinguish iSchools from other units with ALA-accredited master's programs: 1) information beyond agencies is the primary orientation of study; 2) a commitment to multidisciplinarity; and 3) an emphasis on research productivity. While it is tempting to see these as fixed points or positions, they are in fact articulated in a particular context and addressed to those whose primary concern is library and information studies (LIS) education, and are therefore relative. As the origins and emphases of the membership has diversified from its largely LIS, ALA-accredited roots to include programs that approach the information field from quite different disciplinary backgrounds, perspectives, and locations. Sixteen institutional members come from outside North America. Seven do not include graduate programs that prepare students to work in libraries, and most include programs in one or more area, including: information technology, information systems, networks and telecommunications, and related areas. Although it is reasonable to assume that none would find Dillon's three points antithetical to their missions or goals, their commitment to each may, and in fact, does vary. The implied juxtaposition in the Dillon's first point would most likely not resonate with many that do not include LIS programs.
The organization's website (http://ischools.org) describes it as "a collection of Information Schools dedicated to advancing the information field," which "share a fundamental interest in the relationships between information, people, and technology." Recent research examining cocitation patterns, thematic maps, and curriculum indicates, however, that the methods and approaches to the study of information, people and technology are increasingly divergent (Bonnici et al. 2009; Chen 2009; Chu 2012; Wedgeworth, 2013). As of July 2013, the 46 iSchools do not appear to share fixed points or positions common to all; instead they might be said to share a fundamental interest. This interest enables connections and relationships within the organization, but does not exclude similar connections and relationships outside of the organization.

\subsection{Is the structure dynamic and constantly changing?}

While the fundamental interest in the relationships between information, people and technology has been constant throughout the history (and pre-history) of the iSchools organization, criteria for membership (reflected in Dillon's (2012) second and third points of distinction) have become increasingly inclusive over time. As of April 2013, the criteria are explicitly "not rigid" (http://ischools. org/about/apply-to-join/). It is expected that applicants demonstrate substantial sponsored research activity, engagement in the training of future researchers, and commitment to progress in the information field, but how applicants demonstrate these baseline characteristics is left undefined. Particularly in the case of international applications, judgments are to include consideration of norms and circumstances local to the applicant. Over time the iSchools' membership has become increasingly diverse. Its member programs now span the academic disciplines of LIS, computer and information science, and information systems management. While most of the membership continues to be concentrated in North America, European and Asian membership has grown significantly in recent years. The membership of the iSchool organization is dynamic and constantly changing.

There have been several accounts of the history of the iSchools that indicate that the organization grew from informal meetings of a small group of deans of LIS programs (Larsen 2010). Synergy with other types of information programs occurred as this group expanded and began attending meetings of a group organized by the Computer Research Association (CRA), now known as the CRA Deans. The institutional membership of the iSchools and the CRA Deans continues to overlap. A joint meeting of the deans of the two groups was held at the 2013 iConference. 
During the early phase of its development, the iSchool organization was charged with elitism and exclusivity by LIS programs that did not meet the membership criteria (Wallace 2009), but over time the evolution of membership criteria has been accompanied by expansion in the geographic reach and disciplinary affiliations of a dynamic and constantly changing membership.

\subsection{Is there any hierarchy or genealogy that results in some points being inevitably superordinate or prior to others?}

It is important to note at the outset of this discussion of hierarchy and genealogy, that Deleuze and Guattari (1987) do not exclude hierarchy or genealogy from the rhizome metaphor, but instead reject them as structural or generative models of the rhizome itself. Hierarchy and genealogy can, and probably always will, exist within the rhizome, where they function like islands in a sea of infinite connection.

As noted above, the iSchools organization was initially a relatively small collective of fourteen schools united by the desire to "establish broad recognition of the iField and its importance to society" (http://ischools.org/), and a willingness to make a long-term financial commitment to carry this forward. According to Bruce (2010), it was first referred to as the iSchool movement, then the iSchool Project. As this rhetorical positioning implies, the organizational structure was relatively flat and grassroots in its orientation. Officers elected for limited terms on a rotating basis, with the expectation that everyone would take their turn.

As the iSchool movement gained momentum, the organization adapted its membership requirements and organizational structure to include a wider and more diverse range of programs. For those who wished to be engaged and involved without a long-term commitment, an annual membership fee was made available (currently $\$ 500$ per year).

The current organizational structure is at once egalitarian and quasi-hierarchical. It combines the collectivist ideology of its founding members with a two-tiered membership. The inner-circle consists of programs that are willing to make long-term commitment and contribute financially at the higher level. These programs comprise the governing board, known as the iCaucus. Any qualifying annual member willing to commit to the higher financial obligation may apply for standing membership in the iCaucus. A small number of programs holding annual memberships are elected by the iCaucus membership to represent the outer-circle of annual members. These latter are not required to increase their financial commitment while they serve on the iCaucus.

In the previous section, we referred to published histories of the iSchool organization, which document its genealogy from individual perspectives. Deleuze and Guat- tari would classify these as potential genealogies, since they shift and change from individual to individual and over space and time. It is not surprising that the published accounts of the genealogy of the iSchools (Bruce 2010; Larsen 2010; Dillon 2012, etc.) diverge from one another, from the research to date, and from individual participants' experience in several respects. While each genealogy is valid from its own perspective, each differs to some degree from the others. No one genealogy is inevitably superordinate or prior to the others. The challenge for the iSchools is that, while activating potential genealogies and lines of deterritorialization is essential to engaging interest and promoting understanding in and about the iField, to do so is to perpetually risk demolishing the field itself.

\subsection{Is there an open network that can be connected with something else in all of its dimensions?}

Cronin (2005), Wallace (2009), Bruce (2010) and Dillon (2012) frame the iSchools in such a way to distinguish them from other LIS schools, which would seem to imply that the organization has an inside and outside, i.e., that those who are not members for whatever reason are external to the iSchools and therefore not connected to them. On the contrary, one might argue that all ALA-accredited master's programs, for example, are related because they share a set of accreditation standards, whether or not they share an interest in the relationships between people, information and technology, are committed to multidisciplinarity, or emphasize research productivity. Because 18 of the iSchools are ALA-accredited, these are not exclusive categories - they overlap. Some iSchools do not count an ALA-accredited master's program among their offerings; some ALA-accredited master's programs are not represented among the iSchool membership. A third overlapping category extends the size of the rhizome even further: as Dillon (2012) suggests, iSchools share a commitment to multidisciplinary work. This commitment connects each iSchool to other units across their campuses (and potentially, across institutions) that may or may not share their interest in the relationships between people, information and technology. Deleuze and Guattari (1987) call these connections lines of deterritorialization because they deconstruct the simulation of inside/outside. Given the ever-expanding nature of these lines of deterritorialization, the iSchools clearly comprise an open network that can be connected with something else in all of its dimensions. Everything is not an iSchool, but the open network structure and collectivist ideology of the iSchools organization facilitates the potential for its members to be connected in a myriad of ways to things that are not iSchools. 


\subsection{Can every point be connected with every other point and must it?}

In an open network, every point has the potential to connect to every other point, but as described, this characteristic requires more than the potential for connection; it requires that every point 'must' connect to every other point. To understand the nature of this requirement, it is important to clarify Deleuze and Guattari's principle of asignifying rupture.

Botanical rhizomes, such as crabgrass and kudzu, are very difficult to kill because their root systems are extensive, invasive, and difficult to terminate. When a root is cut, new roots sprout behind the cut and extend to fill the space. At a given moment, a dead patch or gap may appear, but this will rapidly fill with new growth. Deleuze and Guattari (1987) name this characteristic the principle of asignifying rupture. Ruptures can and must occur, but they are not significant to the rhizome-as-rhizome. The iSchools organization has already weathered asignifying ruptures in the form of changes in leadership brought on by promotion, reassignment, retirement, and death. Mergers of member institutions with other units on campus are another form of asignifying rupture that the organization has experienced. Other potential ruptures, such as the merger of two members (e.g., the pending merger of the University of Indiana's School of Library and Information Science with the School of Informatics), withdrawal of a member institution, closure of a member program, and changes in curricular orientation or research direction are also likely to be asignifying so long as the space opened by these events is filled and the organization continues to thrive.

At any given moment, a rupture may appear to be significant, even though in the long term it will not be. Similarly, the trajectory of growth may be difficult to analyze based on observation of a moment, since the configuration of the rhizome at that moment may be asignifying. Bonnici et al. (2009) analyzed a variety of data sources to determine whether the formation of the iSchools represented a deliberate split from the discipline of LIS, a conflict in approach to traditional LIS education, or an ingestion of traditional disciplinary content into a new iField. While there was some evidence to support a deliberate split or conflict in approach, most of the evidence pointed to an ingestion of traditional disciplinary content through the mechanism Abbott (2001) calls "fractal cycle." What puzzled Bonnici et al. (2009), was that their initial data, representing the first five years of the iSchools, indicated increased broadening, while Abbott's fractal cycle operates through increased specialization. It is important to note here that that they operationalized the emerging concept of the iField as a discipline that would merge two prior areas of study: information science (IS) as constituted in the discipline of computer science and information science (CIS), and IS as constituted in LIS. Accordingly, the cocitation data used in their study was drawn across two indices: the Web of Science and the Web of Social Science. When these results were placed in the context of multiple comparable slices of time from 1967 on, it became clear that the overall trend in the development of the discipline has been toward specialization. Abbott's distinction between 'fractal distinction' and 'fractal distinction in time' is useful in the analysis of the appearance of rupture brought forth by the founding of the iSchools, because it accounts for the difference between the human experience of time and the achronicity of the rhizome, which in turn makes it possible to state that in the case of the iSchools-as-rhizome, every point is connected to every other point and must be.

It is important to note, that the iField as operationalized by Bonnici et al. (2009) may not be consistent with the characteristics of the iField as it emerges. It may ingest other disciplines that were not included in the study (e.g., information systems); the two IS disciplines may merge and then split into different configurations rather than merging and specializing along a common trajectory; or irreconcilable conflict may develop between the two IS disciplines and the historical split be reinforced.

One question that emerges is whether the effects of the rupture surrounding the emergence of the iSchools will continue along the lines of deterritorialization established in the discipline(s) of IS (e.g., toward specialization), or if the rupture signifies a change in direction. If the rupture is asignifying, the long-term trajectory of the iField will continue toward increased specialization even as it ingests other disciplinary content. If the rupture is signifying, the content of all of the participating disciplines will be profoundly altered, and a unified iField will not emerge.

\subsection{Conclusions}

As Bruce (2010) suggests, the information field has struggled to define its identity for more than forty years. This struggle has manifested itself in a number of polarizations over time, including content focus (information science v. library science), orientation (discipline v. profession), and purpose (theory v. practice). Most recently, the struggle has crystalized around the formation of the iSchools organization, and the anticipated consequences of that formation for adjacent academic units, particularly library and information science (LIS) and computer and information science (CIS) programs. The founders of the iSchools organization initiated this most recent phase in the struggle with the expressed intention of creating a marketable identity to raise their academic and research profiles nationally and internationally. The growth of the organization indicates that they have had considerable success in drawing at- 
tention to themselves, but has this brought them any closer to "articulat[ing] the essence of an 'information school" and the "information field" (Bruce 2010, 39)?

Chen (2009) found that, between 2000 and 2007, several thematic research topic bursts (e.g., peer-to-peer networks, routing protocols, web search engines, biomedical literature) co-existed alongside more traditional library and information science topic areas, validating Bruce's assessment that the goal of the first gathering of iSchool faculty and students in 2006 was ambitious and unattainable, because it "risks the exclusion of voices, the alienation of important partners, and the creation of barriers that can threaten future collaboration" (Bruce 2010, 39).

To attribute the lack of clarity and definition of the iField solely to the discipline's immaturity may, therefore, be to miss the point. If the iField is as rhizomorphic as the organization that strives to promote it, crystallization of disciplinary identity may be more harmful than helpful, since it may represent significant rupture of its rhizomorphic characteristics, resulting in stagnation of its dynamic, open, and interconnected nature. Whether it is that the iField is still in an early stage of crystallization of disciplinary identity, or that it is truly rhizomorphic and therefore dynamic and open, the observable trend toward striving to find and articulate common ground is likely to continue unresolved for some time.

\section{References}

Abbott, Andrew. 2001. Chaos of disciplines. Chicago: University of Chicago Press.

Bonnici, Laurie J., Subramaniam, Manimegalai M. and Burnett, Kathleen. 2009. Everything old is new again: the evolution of library and information science education from LIS to iField. Journal of education for library and information science 50: 263-74.

Bruce, Harry. 2010. The audacious vision of information schools. In 2010 International Symposium on the Transformation and Innovation of Library and Information Science, November 16-17, 2010, Taipei, Taiwan, pp. 39-45. Available http://www.glis.ntnu.edu.tw/2010conference/docs/ proceeding039-045.pdf.

Burnett, Kathleen. 1993a. Toward a theory of hypertextual design. Postmodern culture 3n2. Available http://muse. jhu.edu $/$ login?auth $=0 \&$ type $=$ summary\&url $=/$ journals $/$ postmodern_culture/v003/3.2burnett.html.
Burnett, Kathleen. 1993b. The scholar's rhizome: network communication issues. Electronic journal on virtual culture 1n2. Available http://serials.infomotions.com/aejvc/ aejvc-v1n02-burnett-scholars.txt.

Chen, Chaomei. 2009. Thematic maps of 19 iSchools. Proceedings of the American Society for Information Science and Technology 45: 1-12.

Chu, Heting, 2012. iSchools and non-iSchools in the USA: an examination of their master's programs. Education for information 29: 1-17

Cronin, Blaise. 2005. An I-dentity crisis? The information schools movement. International journal of information management 25: 363-5.

Deleuze, Giles, and Guattari, Félix. 1987. A thousand plateaus. Minneapolis: University of Minnesota Press.

Dillon, Andrew. 2012. What it means to be an Ischool. Journal of education for library and information science 53: 267-73.

Duffy, Thomas, and Cunningham, Donald J. 1996. Constructivism: implications for the delivery of instruction. In Jonassen, David H., ed., Handbook of research for educational communications and technology. New York: Macmillan, pp.170-99.

Larsen, Ronald L. 2010. iSchools. In Encyclopedia of library and information sciences, third edition. London: Taylor \& Francis, pp. 3018-23.

Lemke, Jay L. 1993. Hypermedia and higher education. Interpersonal computing and technology 1n2. Available http:// www.helsinki.fi/science/optek/1993/n2/lemke.txt.

Moulthrop, Stuart. 1992. Toward a rhetoric of informating texts. In Lucarella, Dario, Nanard, Jocelyne, Nanard, Marc and Paolini, Paolo, eds., ECHT '92 Proceedings of the ACM Conference on Hypertext. New York: Association for Computing Machinery, pp. 171-80.

Schuh, Kathy L. and Cunningham, Donald J. 2004. Rhizome and the mind: describing the metaphor. Semiotica 149: 325-42.

Wallace, Danny P. 2009. The iSchools, education for librarianship, and the voice of Doom and Gloom. Journal of academic librarianship 35: 405-9.

Wedgeworth, Robert. 2013. Certain characteristics of iSchools compared to other LIS programs. Ph.D. dissertation. New Jersey: Rutgers The State University of New Jersey - New Brunswick. Available http://rucore. libraries.rutgers.edu/rutgers-lib/39689/ 